ro

تقدير الكفاءة التقتية والإقتصادية لأهم المحاصيل المنزرعة في محافظة شمال سيناء

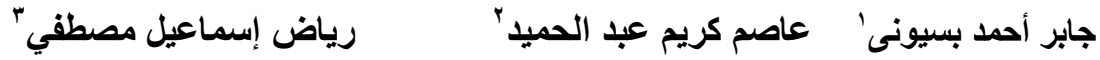

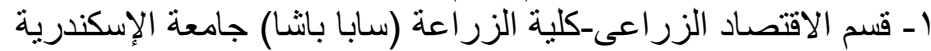

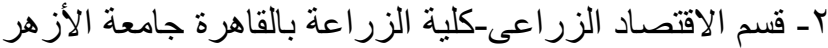

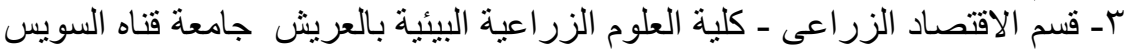

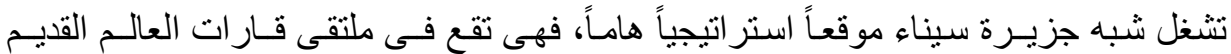

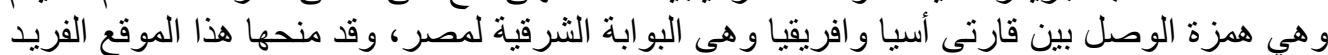

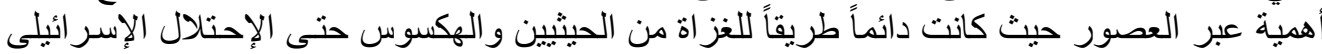

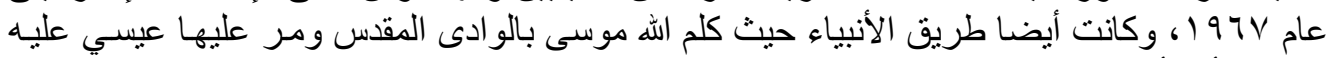

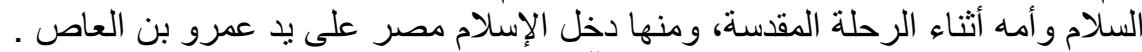

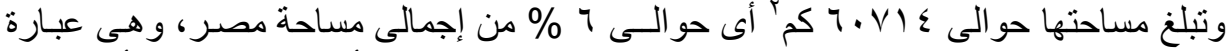

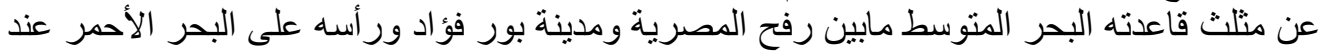

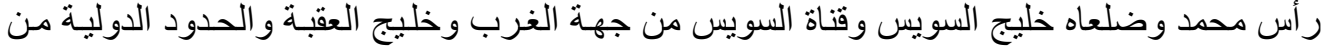
جهة الثرق.

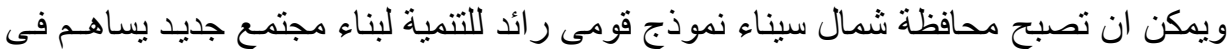

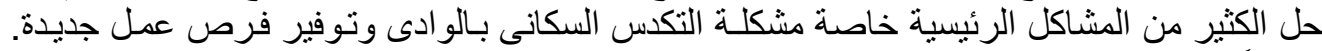

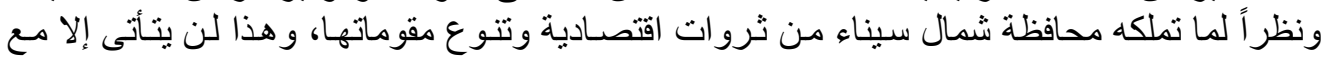

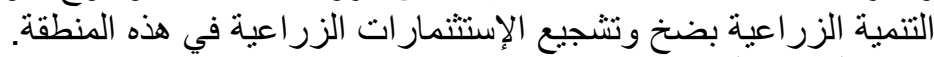

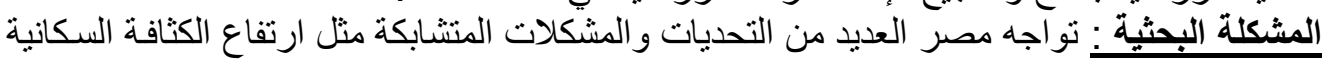

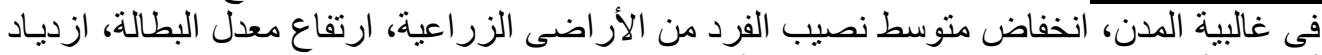

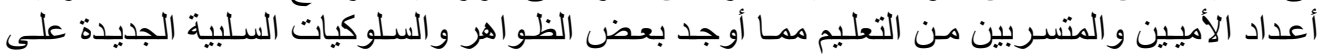

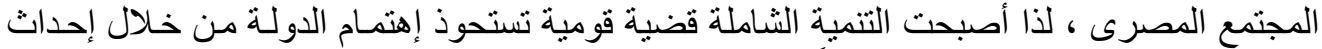

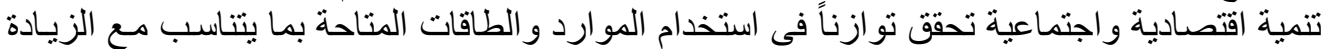

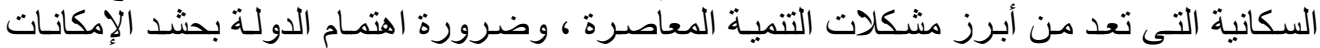

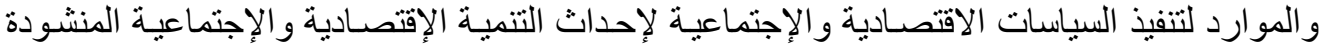
في محافظة شمال سيناء.

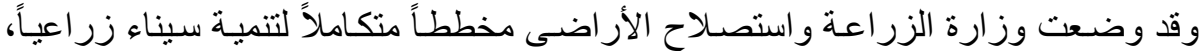

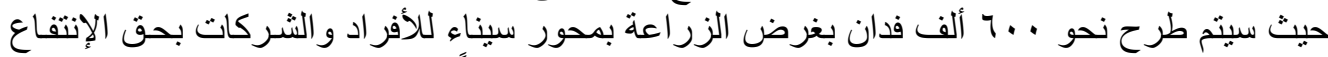

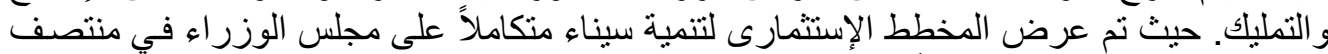

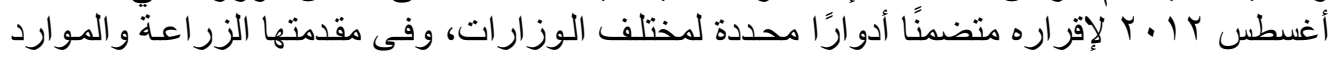

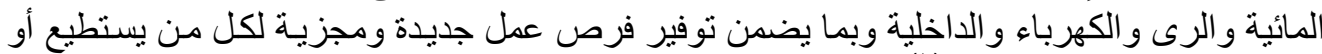

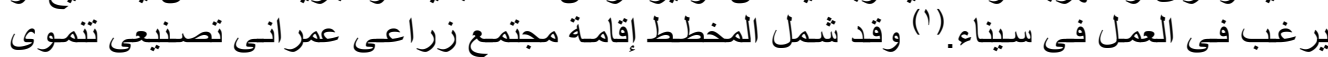

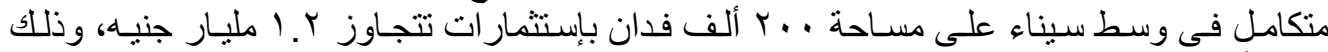

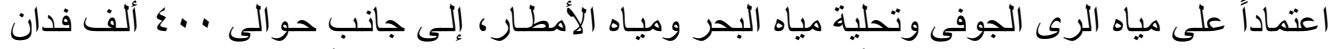

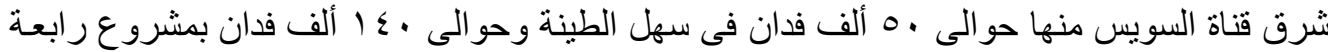

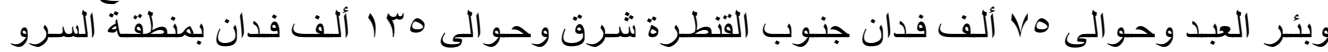

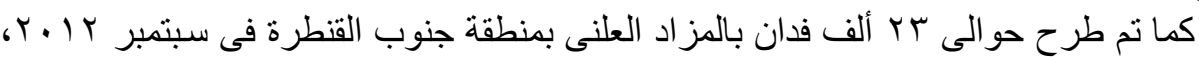
و والقو ارير.

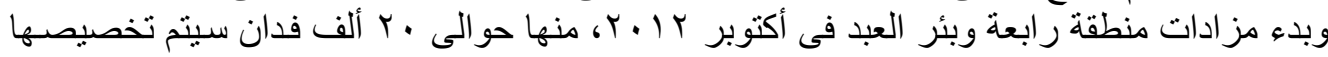

( $\left.{ }^{1}\right)$ www. gate.ahram.org.eg

Fayoum J. Agric. Res. \& Dev., Vol. 26, No. 2, July, 2012 


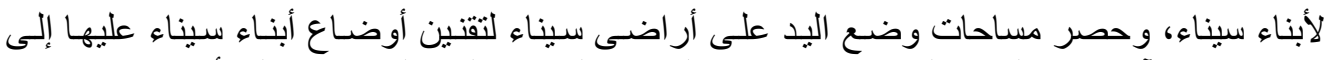
جانب حصر آبار مياه الرى بالتنسيق مع وزارة الموارد المائية والرى لتوزيناء التيعها على أبناء أبناء سيناء.

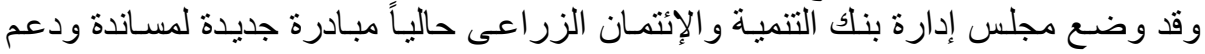

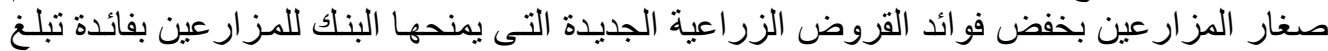

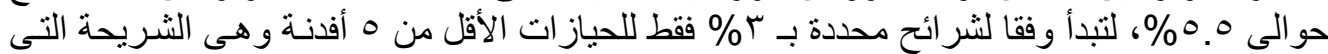

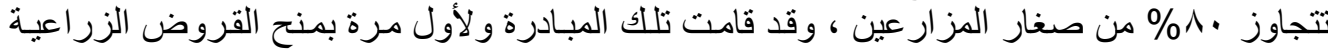

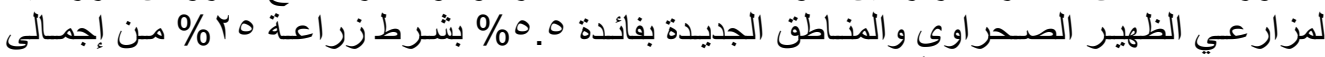

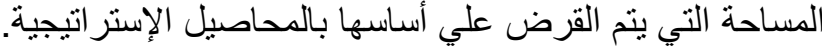

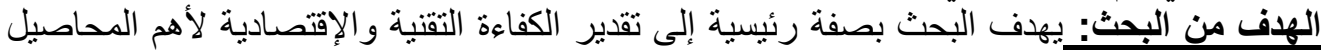

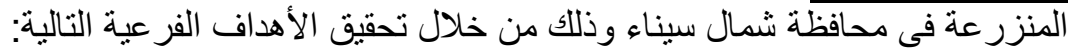

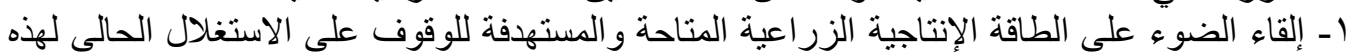

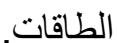

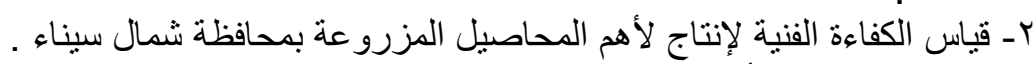

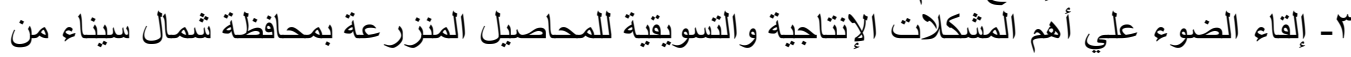

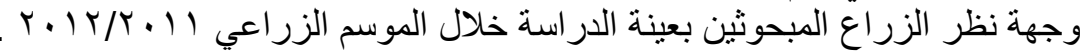

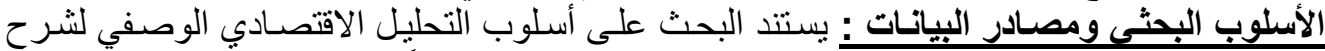

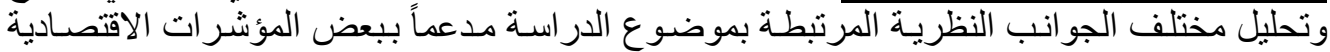
ووسائل التقدير القياسي المستخدمة لتقدير الكفاءة الفنية بإستخدام المنهجيات : (أ) الحدوديـة العشوائية The Stochastic Frontier Analysis (SFA) لتقدير دو ال الإنتاج بطريقة المربعات الصغرى العادية Ordinary Least Squares (OLS) وطريقة أعظم احتمال

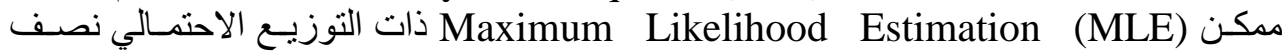
الطبيعـي Half-Normal Distribution و التوزيــع الاحتمـالي المبتـور .Distribution

(ب) الحدوديـة المحددة The Deterministic Frontier Approach بإسـتخدام تحليل مغلف البيانات Data Envelopment Analysis (DEA) وفقاً لمفهومي العائد الثابت للسعة (CRS) Variable Returns To Scale و العائد المتغير للسعة Constant Returns To Scale Scale لتقدير كل من الكفاءة التقنية Technical Efficiency (TE) وكفاءة السعة TS2) . Efficiency (SE)

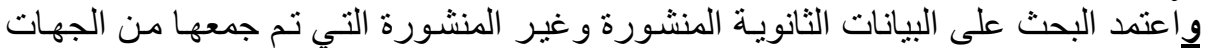

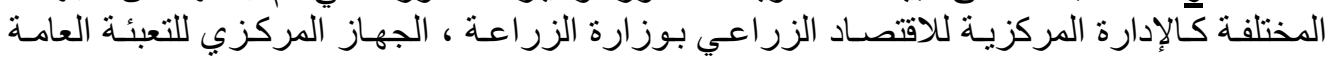

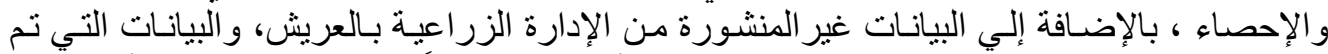

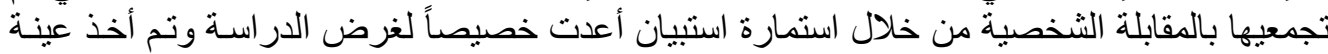

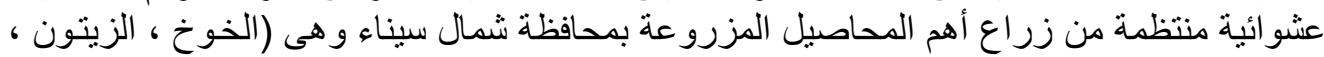

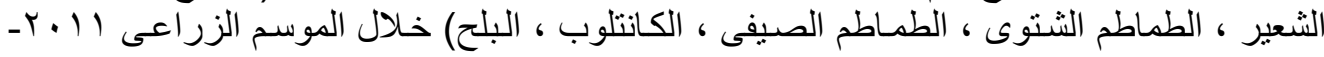

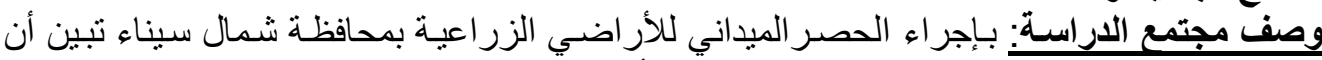

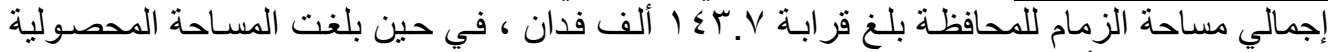

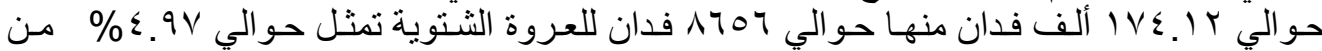

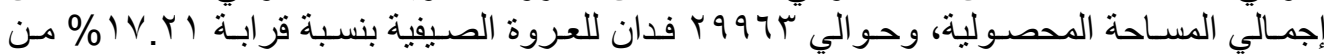

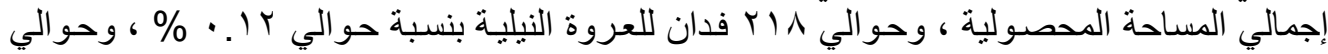

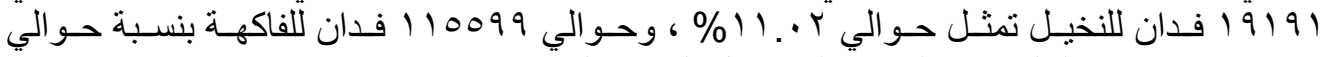

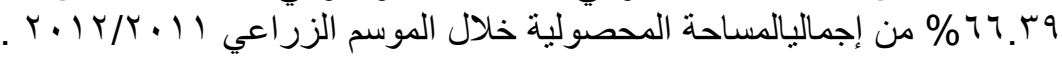

Fayoum J. Agric. Res. \& Dev., Vol. 26, No. 2, July, 2012 


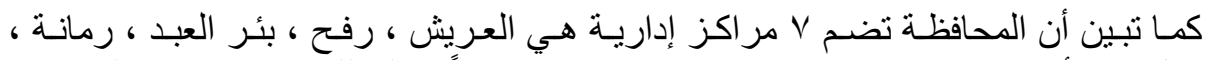

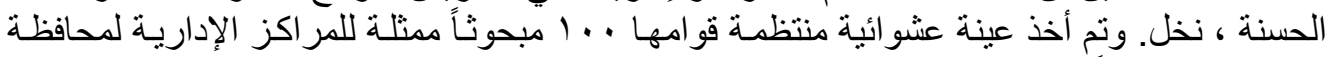

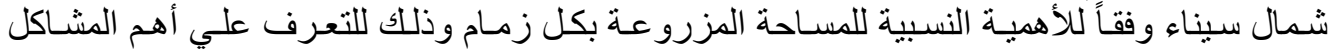

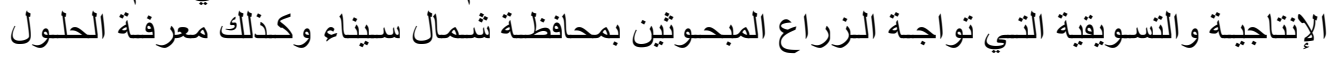

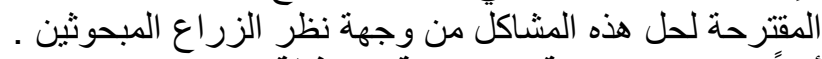

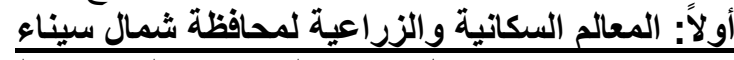

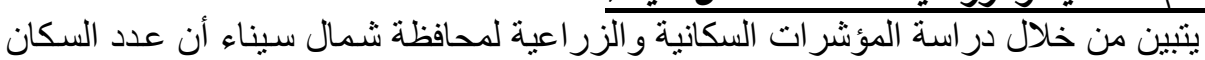

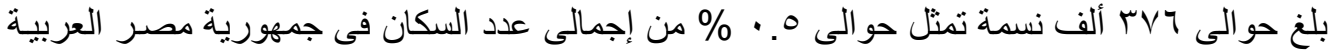

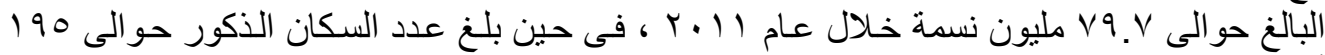

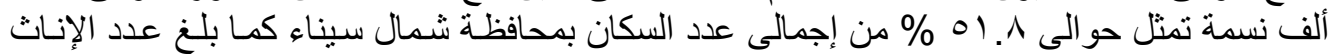

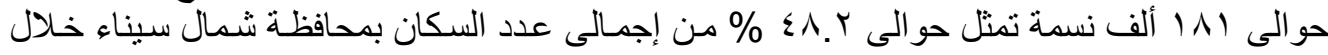

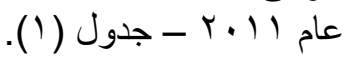

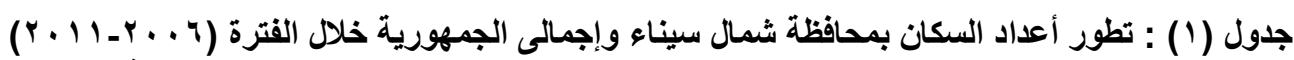
(العدد :مليون نسمة (العزبة)

\begin{tabular}{|c|c|c|c|c|c|c|c|}
\hline & \multicolumn{3}{|c|}{ شمال سيناء } & \multicolumn{3}{|c|}{ جمهورية } & \multirow{2}{*}{ السنة } \\
\hline$\%$ & جملة & إناث & ذكور & جملة & إناث & ذكور & \\
\hline 0.5 & 0.343 & 0.165 & 0.178 & 72.5 & 35.4 & 37.1 & 2006 \\
\hline 0.5 & 0.35 & 0.168 & 0.182 & 73.8 & 36.1 & 37.7 & 2007 \\
\hline 0.5 & 0.357 & 0.172 & 0.185 & 75.3 & 36.8 & 38.5 & 2008 \\
\hline 0.5 & 0.364 & 0.175 & 0.189 & 76.8 & 37.6 & 39.2 & 2009 \\
\hline 0.5 & 0.37 & 0.178 & 0.192 & 78.2 & 38.3 & 39.9 & 2010 \\
\hline 0.5 & 0.376 & 0.181 & 0.195 & 79.7 & 39.0 & 40.7 & 2011 \\
\hline 0.5 & 0.363 & 0.174 & 0.188 & 76.89 & 37.67 & 39.21 & المتوسط \\
\hline
\end{tabular}

المصدر : جمعت وحسبت من الجهاز المركزى للتعبئة العامة والإحصاء -الكتاب الإحصائى السنوى ـ-

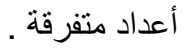

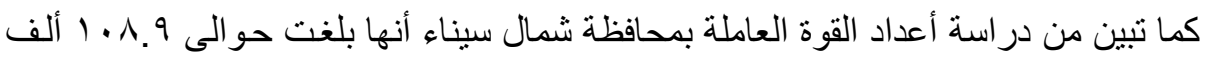

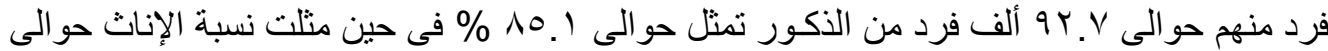

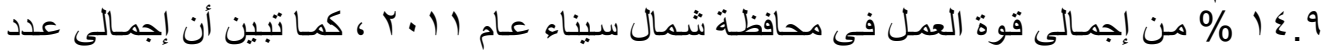

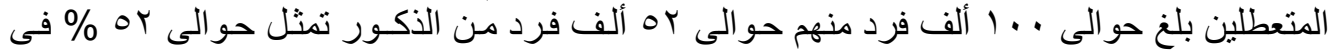

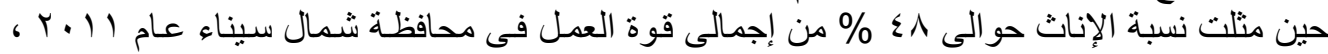

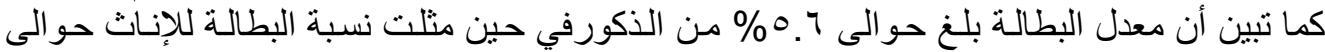

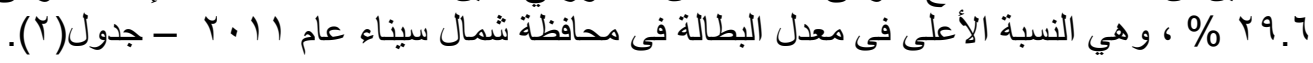

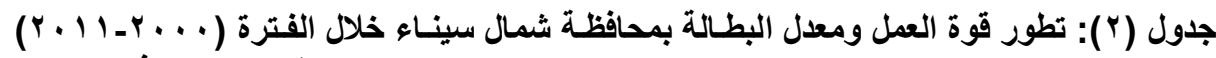

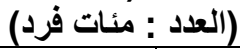

\begin{tabular}{|c|c|c|c|c|c|c|c|c|c|c|}
\hline \multicolumn{3}{|c|}{ معدل البطالة } & \multicolumn{3}{|c|}{ المتعطلين } & مسناهمة & \multicolumn{3}{|c|}{ قوة العمل } & \multirow{2}{*}{ السنة } \\
\hline جملة & إناث & ذكور & جملة & إناث & ذكور & $\%$ & جملة & إناث & ذكور & \\
\hline 10.2 & 30.7 & 4.2 & 81 & 55 & 26 & 22.6 & 792 & 179 & 613 & 2000 \\
\hline
\end{tabular}

Fayoum J. Agric. Res. \& Dev., Vol. 26, No. 2, July, 2012 
rᄉ

\begin{tabular}{|c|c|c|c|c|c|c|c|c|c|c|}
\hline 13.2 & 30.3 & 7.0 & 110 & 67 & 43 & 26.4 & 836 & 221 & 615 & 2001 \\
\hline 10.0 & 20.0 & 7.9 & 84 & 29 & 55 & 17.2 & 841 & 145 & 696 & 2002 \\
\hline 15.3 & 32.4 & 10.6 & 146 & 66 & 80 & 21.3 & 956 & 204 & 752 & 2003 \\
\hline 12.7 & 35.6 & 7.6 & 104 & 53 & 51 & 18.1 & 822 & 149 & 673 & 2004 \\
\hline 16.1 & 19.7 & 15.1 & 140 & 39 & 101 & 22.8 & 867 & 198 & 669 & 2005 \\
\hline 14.1 & 23.9 & 11.4 & 132 & 48 & 84 & 21.5 & 937 & 201 & 736 & 2006 \\
\hline 3.8 & 13.3 & 1.4 & 37 & 26 & 11 & 20.3 & 967 & 196 & 771 & 2007 \\
\hline 3.8 & 9.9 & 2.5 & 39 & 18 & 21 & 17.8 & 1018 & 181 & 837 & 2008 \\
\hline 12.8 & 23.0 & 10.5 & 131 & 43 & 88 & 18.1 & 1022 & 185 & 836 & 2009 \\
\hline 9.1 & 26.9 & 5.4 & 99 & 50 & 49 & 17.1 & 1089 & 186 & 903 & 2010 \\
\hline 9.2 & 29.6 & 5.6 & 100 & 48 & 52 & 14.9 & 1089 & 162 & 927 & 2011 \\
\hline $\mathbf{1 1}$ & $\mathbf{2 5}$ & $\mathbf{7}$ & $\mathbf{1 0 0}$ & $\mathbf{4 5}$ & $\mathbf{5 5}$ & $\mathbf{2 0}$ & $\mathbf{9 3 6}$ & $\mathbf{1 8 4}$ & $\mathbf{7 5 2}$ & المتوست \\
\hline
\end{tabular}

المصدر : جمعت وحسبت من الجهاز المركزى للتعبئة العامة والإحصاء ـالكتاب الإحصائى السنوى -

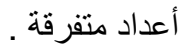

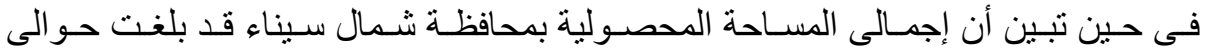

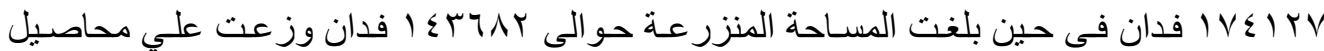

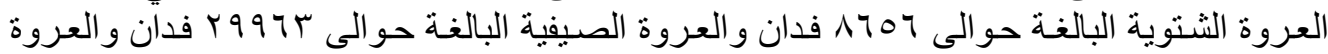

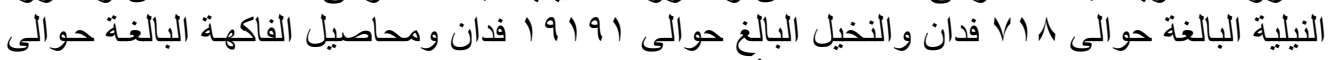

1100999

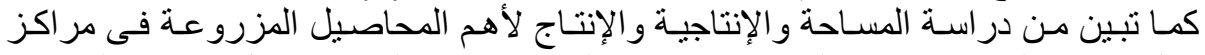

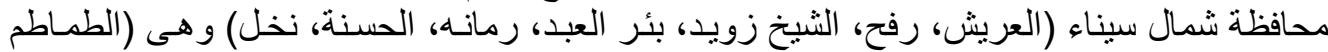

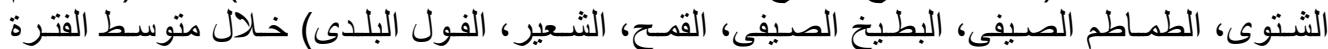

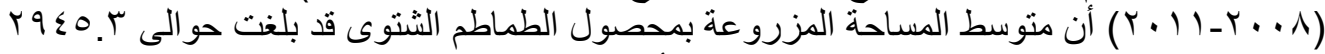

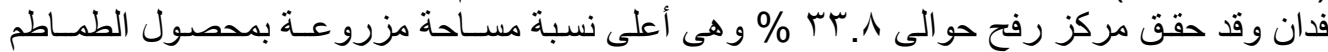

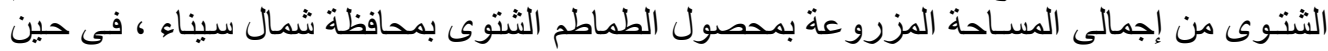

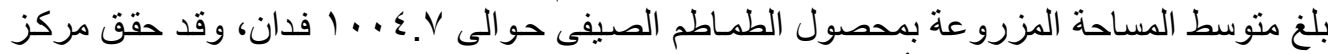

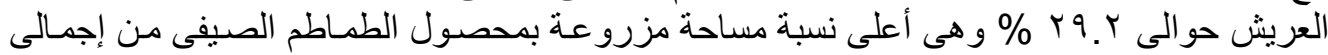

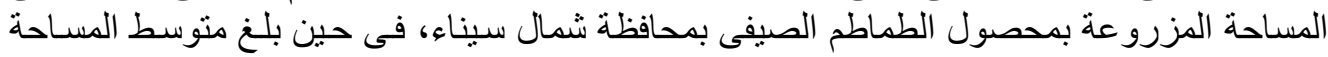

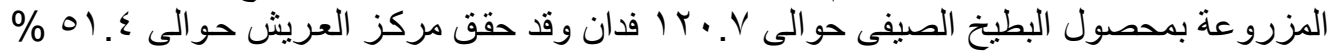

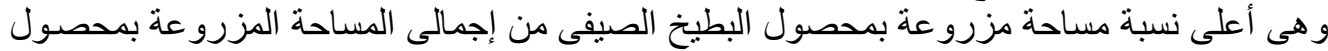

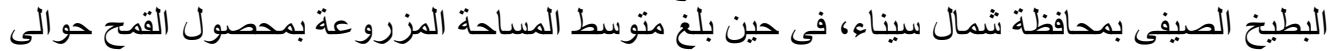

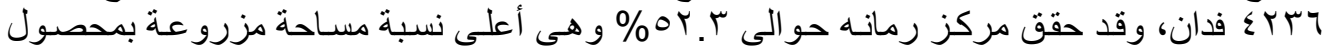

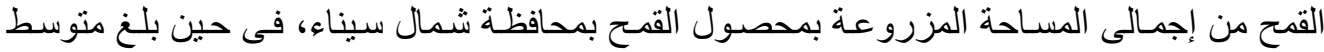

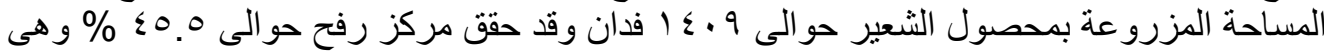

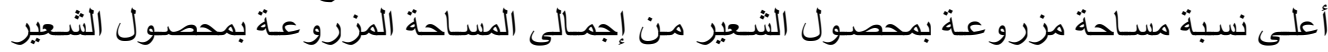

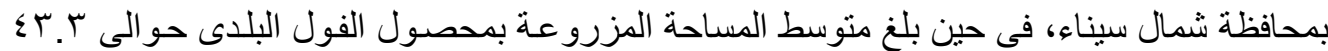

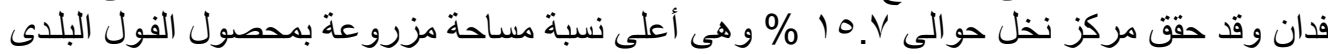

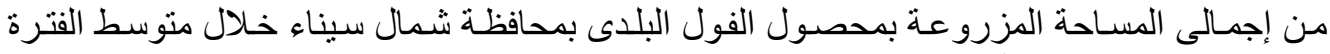

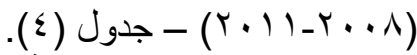

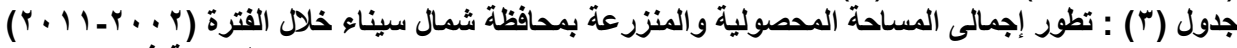
(المساحة:فئان)

\begin{tabular}{|c|c|c|c|c|c|c|c|c|c|c|c|}
\hline معدل & 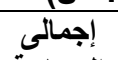 & & & & النيلإ. & الع & صيف & |العر| & الشتوية & ل) & \\
\hline إلارضتذام & المنزرعة & المحصولية & & النذ & خضر & & הin & 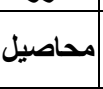 & ذض & & \\
\hline 1.0 & & & & & & & & & & & \\
\hline 11 & 137694 & 151424 & 2830 & 007 & 1550 & 100 & 1878 & 02 & 628 & & J \\
\hline
\end{tabular}

Fayoum J. Agric. Res. \& Dev., Vol. 26, No. 2, July, 2012 
rq

\begin{tabular}{|c|c|c|c|c|c|c|c|c|c|c|c|}
\hline 1.1 & 180161 & 195868 & 91195 & 8152 & 1318 & 88 & 45852 & 188 & 10040 & 39034 & 2004 \\
\hline 1.1 & 173655 & 182690 & 89589 & 8299 & 1121 & 78 & 17001 & 175 & 10469 & 55958 & 2005 \\
\hline 1.1 & 165736 & 177243 & 92884 & 8092 & 1552 & 99 & 9107 & 749 & 9604 & 55156 & 2006 \\
\hline 1.5 & 119367 & 173314 & 96300 & 7890 & 2150 & 125 & 469 & 3205 & 8810 & 54365 & 2007 \\
\hline 1.1 & 152405 & 164834 & 130177 & 8470 & 2753 & 489 & 8800 & 587 & 9196 & 4362 & 2008 \\
\hline 1.1 & 154745 & 165583 & 125972 & 9092 & 3526 & 411 & 16526 & 108 & 9599 & 350 & 2009 \\
\hline 1.0 & 184801 & 191568 & 157877 & 9760 & 2515 & 466 & 10383 & 420 & 10019 & 128 & 2010 \\
\hline 1.2 & 143682 & 174127 & 115599 & 19191 & 602 & 116 & 29515 & 448 & 8590 & 66 & 2011 \\
\hline $\mathbf{1 . 1}$ & $\mathbf{1 5 4 2 8 3}$ & $\mathbf{1 7 1 2 4 7}$ & $\mathbf{1 0 8 6 9 2}$ & $\mathbf{9 4 8 2}$ & $\mathbf{1 8 9 1}$ & $\mathbf{2 0 9}$ & $\mathbf{1 5 2 6 1}$ & $\mathbf{6 3 0}$ & $\mathbf{9 5 1 9}$ & $\mathbf{2 5 5 6 4}$ & $\mathbf{2 5 0}$ \\
\hline
\end{tabular}

المصدر : جمعت وحسبت من: المبر

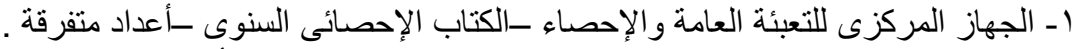

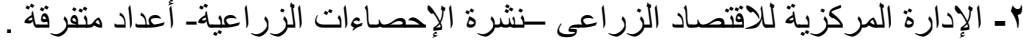

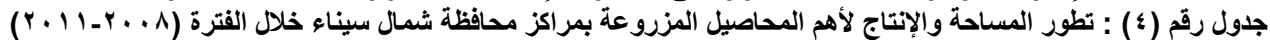

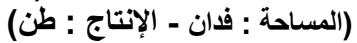

\begin{tabular}{|c|c|c|c|c|c|c|c|c|c|c|c|c|}
\hline \multicolumn{4}{|c|}{ بطيخ صيفي } & \multicolumn{4}{|c|}{ طماط صيفى } & \multicolumn{4}{|c|}{ طماطم شتوى } & \multirow[b]{2}{*}{ المركز } \\
\hline إنتاج & إنتاجية & $\%$ & مساحة & إنتاج & إنتاجية & $\%$ & مساحةً & إنتاج & إنتاجية & $\%$ & مساحةً & \\
\hline 371.3 & 5.7 & 51.4 & 62 & 3499 & $\begin{array}{ll}11.7 \\
\end{array}$ & 29.2 & 293.7 & 4254 & 12 & 12.6 & 370 & العريش \\
\hline 77 & 9.7 & 6.6 & 8 & 1335 & 8.7 & 13.8 & 138.3 & 9768 & 11.7 & 33.8 & 995.3 & رفح \\
\hline 214.7 & 11.2 & 15.7 & 19 & 3371 & $\begin{array}{ll}11.7 \\
\end{array}$ & 26.3 & 264.3 & 8491 & 16.3 & 17.6 & 517.7 & الثيخ زويد \\
\hline 21.3 & 1.3 & 4.4 & 5.3 & 667 & 8 & 8.3 & 83.3 & 2472 & 6.3 & 16.2 & 476 & بئز العبد \\
\hline 27.3 & 4.7 & 4.1 & 5 & 2739 & 13 & 21.0 & 210.7 & 4236 & 6 & 16.0 & 470.3 & رمانه \\
\hline 10 & 1 & 2.7 & 3.3 & 39.3 & 3.7 & 1.4 & 14 & 0 & 0 & 0.0 & 0 & الحسنة \\
\hline 36 & 0.7 & 14.9 & 18 & 0.7 & 0.7 & 0.0 & 0.3 & 1480 & 7.5 & 3.9 & 116 & ن نذل \\
\hline 757.7 & 4.9 & 100 & 120.7 & \begin{tabular}{|l|l|}
11649.3 \\
\end{tabular} & 8.2 & 100 & 1004.7 & $\begin{array}{l}30701.0 \\
\end{array}$ & 8.5 & 100 & 2945.3 & الإجمالي \\
\hline \multicolumn{4}{|c|}{ الفول البلاى } & \multicolumn{4}{|c|}{ الثعير } & \multicolumn{4}{|c|}{ ألقمح } & المر كي \\
\hline إنتاج & إنتاجية & $\%$ & مساحة & إنتاج & إنتاجية & $\%$ & مساحةً & إنتاج & إنتاجية & $\%$ & مساحةً & المرجز \\
\hline 54 & 4.3 & 8.9 & 10.7 & 1730 & 5 & 34.4 & 346 & 401.2 & 4.2 & 3.8 & 112 & العريش \\
\hline 0 & 0 & 0.0 & 0 & 2285 & 5 & 45.5 & 457 & 2581 & 2.6 & 34.9 & 1028 & رفح \\
\hline 0 & 0 & 0.0 & 0 & 410 & 5 & 8.2 & 82 & 3049 & 1.2 & 47.9 & 1410 & الثيخ زويد \\
\hline 41 & 2 & 11.4 & 13.7 & 924 & 6 & 15.3 & 154 & 977.2 & 7.2 & 4.6 & 136.3 & بئز العبد \\
\hline 0 & 0 & 0.0 & 0 & 690 & 2 & 34.3 & 345 & 2544 & 2.3 & 52.3 & 1541 & رمانه \\
\hline 0 & 0 & 0.0 & 0 & 0 & 0 & 0.0 & 0 & 0.7 & 0.3 & 0.0 & 0.7 & الحسنة \\
\hline 57 & 3 & 15.7 & 19 & 100 & 4 & 2.5 & 25 & 38.3 & 4.0 & 0.3 & 8.7 & نذل \\
\hline 152 & 1.3 & 100 & 43.3 & 6139.0 & 3.9 & 100 & 1409.0 & 9590.8 & 3.1 & 100 & 4236.0 & الإجمالي \\
\hline
\end{tabular}

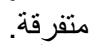

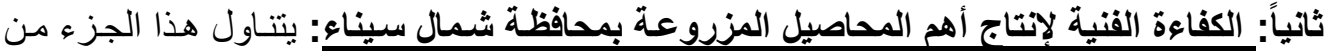

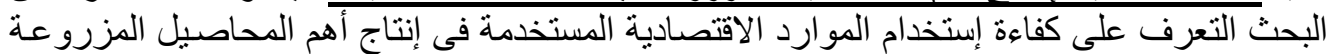

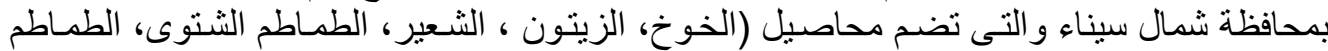

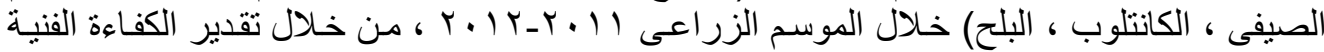

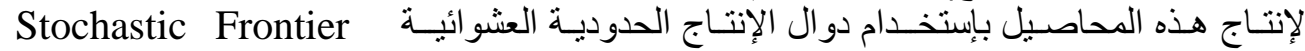
Analyses (SFA) . Deterministic Envelopment Analysis (DEA)

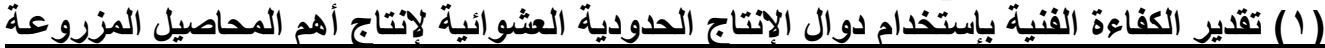

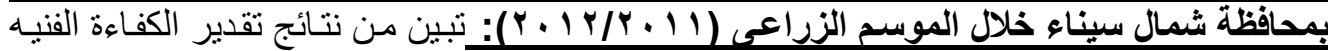

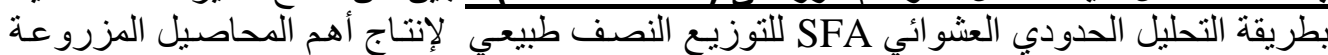

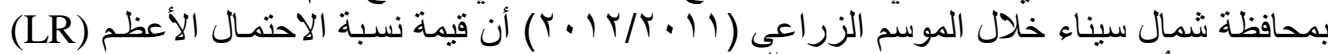

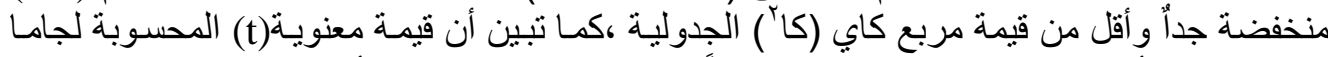

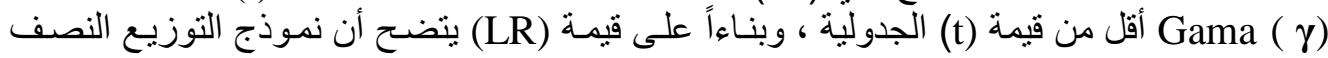
طبيعي غير معنوي . من

Fayoum J. Agric. Res. \& Dev., Vol. 26, No. 2, July, 2012 
$\mu$

كما تبين من نتائج تقدير الكفاءة الفنيه بطريقة التحليل الحدودي العشوائي SFA للتوزيع المبتور

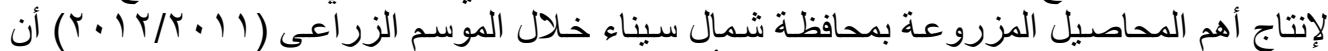

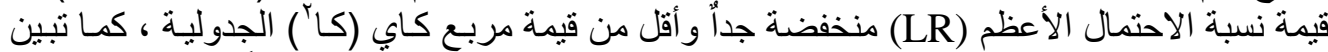

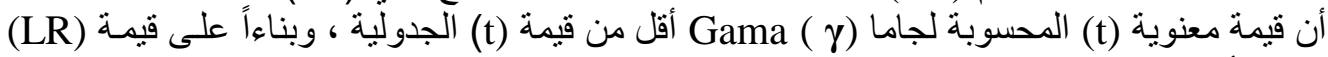
يتضح أن نموذج التوزيع المبتور غئه فير معنوي. ونستخلص مما سبق أنـه بتقدير الكفـاءة الفنيـه بإستخدام المنهجيـة الحدوديـة العشو ائية لإنتاج

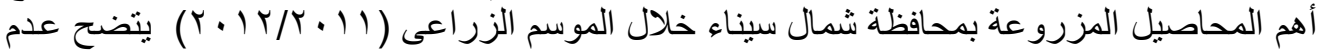

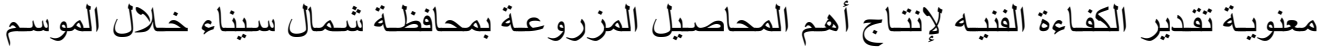

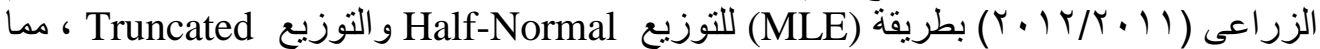
يشير إلىى أفضـلية منهجيـة Envelopment Analysis تحليل الحدودية العشو ائية (SFA).

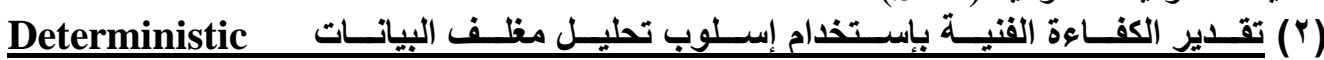

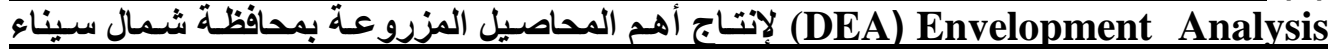
خلال الموسم الزراعى (11)

يتتاول هذا الجزء تقدير الكفاءة الفنية بإستخدام إسلوب تحليل مغلف الفيل البيانـات (DEA) لإنتاج

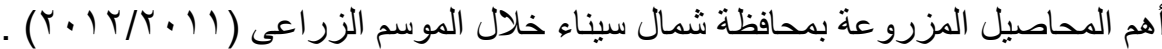

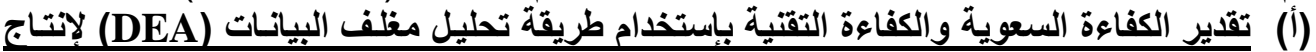

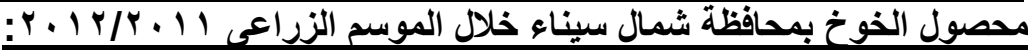

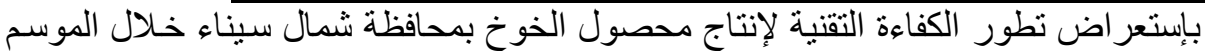

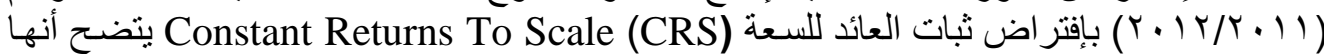

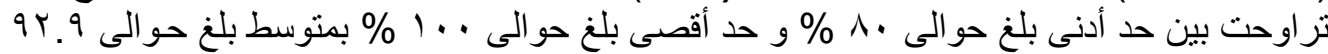

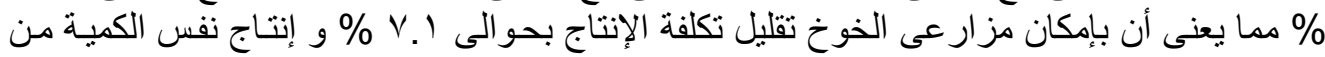

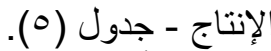

أما فى ظل افتر اض تغير العائد إلى السعة (VRS) Variable Returns To Scale (VRS

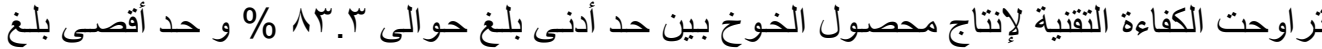

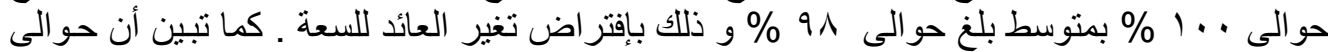

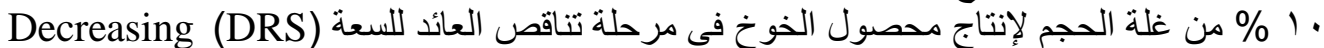

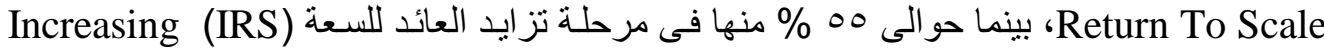
. Return To Scale

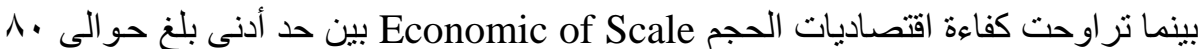

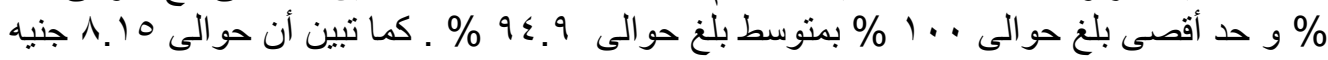

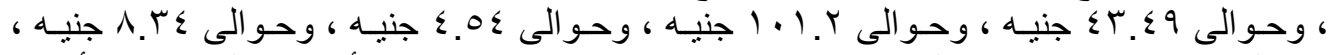

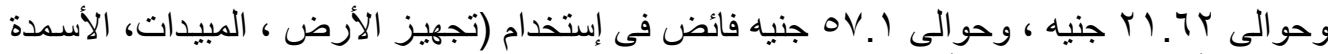

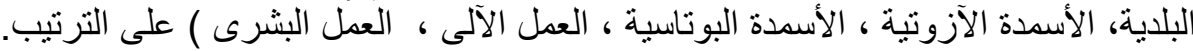

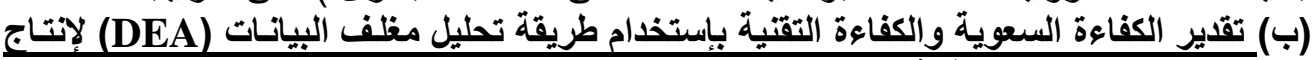

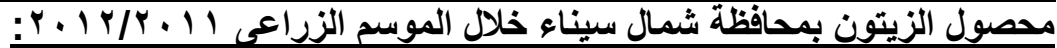

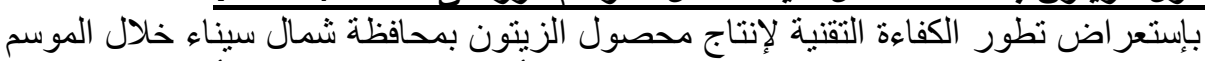

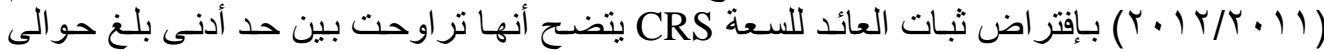

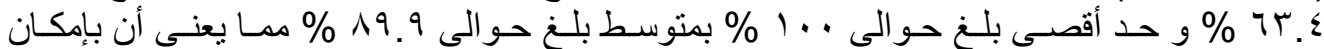

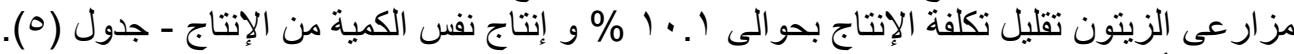
أما فى ظل افتر اض تغير العائد إلى السعة VRS فقد تراوحت الكفاءة التقنية لإنتاج محصول

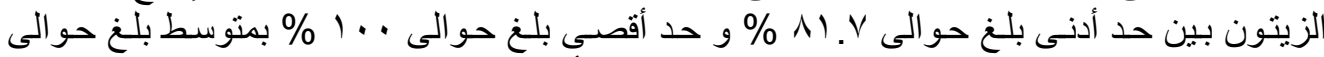

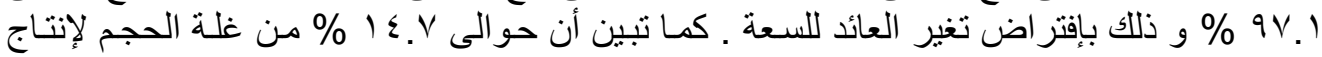

Fayoum J. Agric. Res. \& Dev., Vol. 26, No. 2, July, 2012 
M

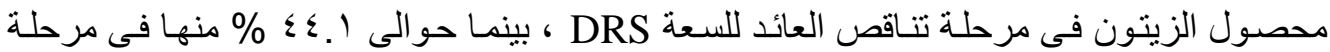

تز ايد العائد للسعة النون

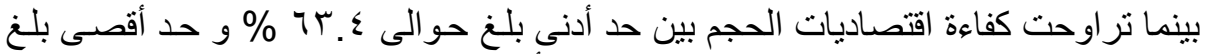

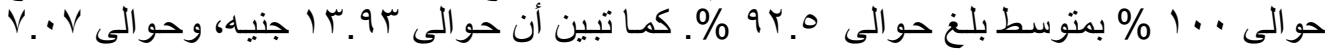

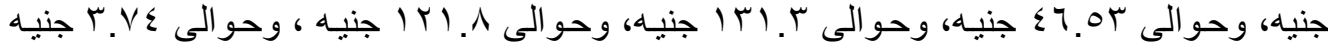
فائض فى إستخدام (تجهيز الأرض، التقاوى، المبيدات، الأسمدة البلدية، العمل الآلى ، العمل البشرى) على الترتيب.

(ج) تقدير الكفاءة السعوية والكفاءة التقية بإستخدام طريقة تحليل مغلف البيانـات (DEA) لإنتاج

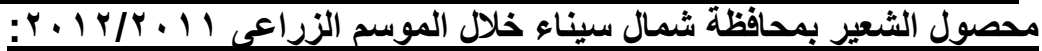

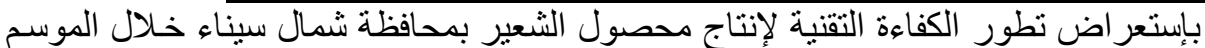

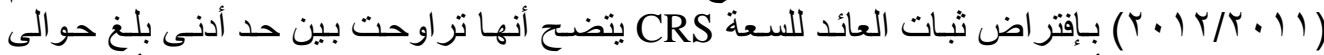

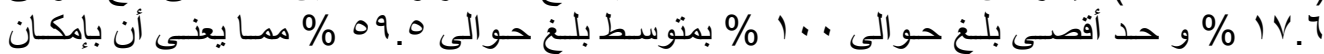

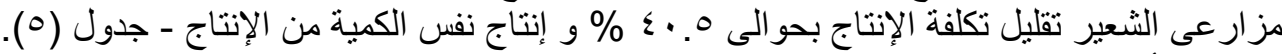

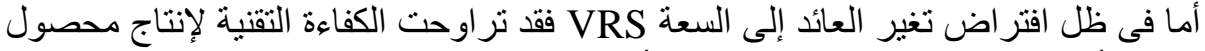

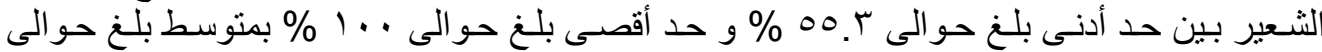

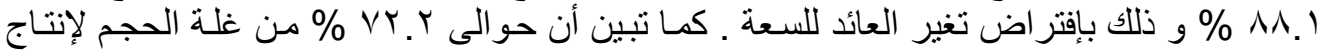

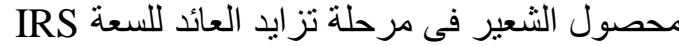

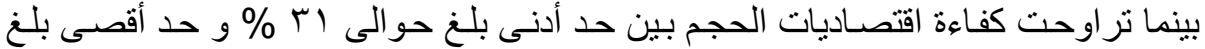

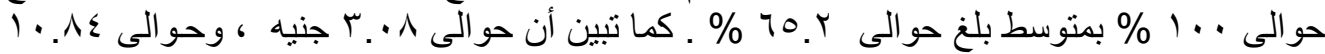

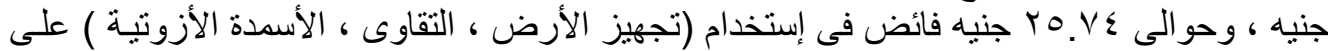

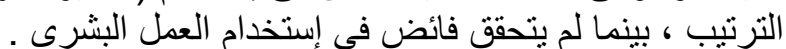

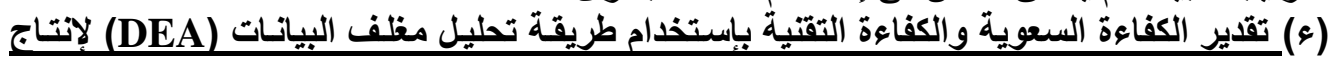

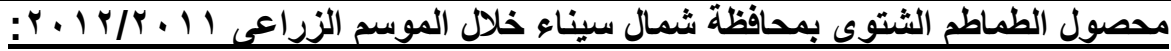

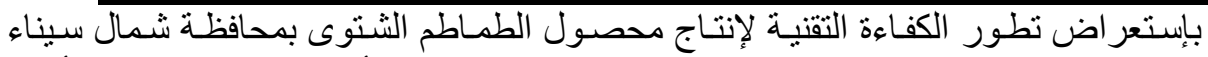

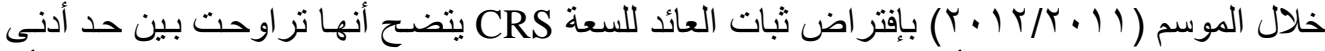

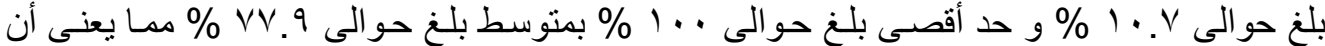

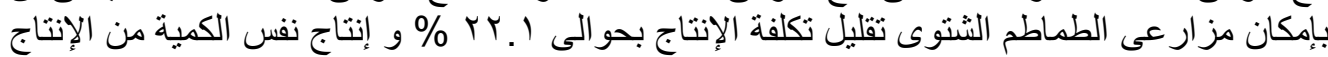

-

أما فى ظل افتر اض تغير العائد إلى السعة VRS فقد تراوحت الكفاءة التقنية لإنتاج محصول

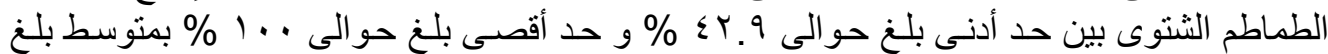

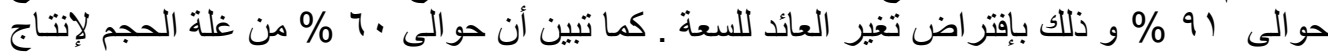

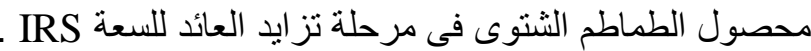

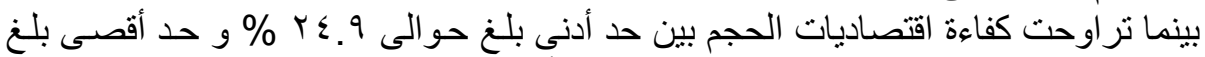

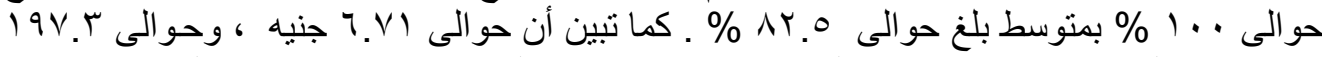

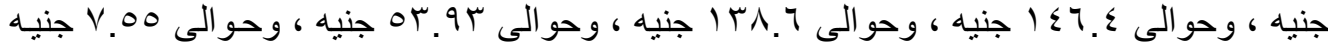

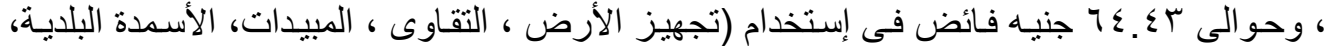

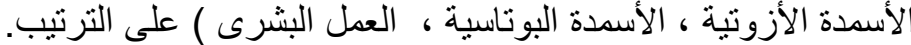

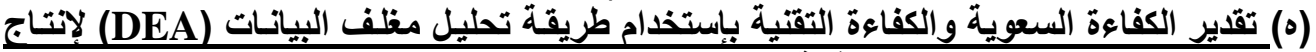

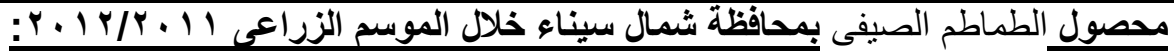

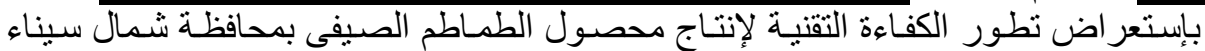

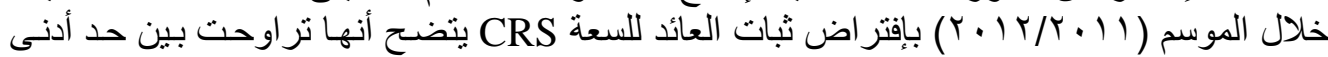

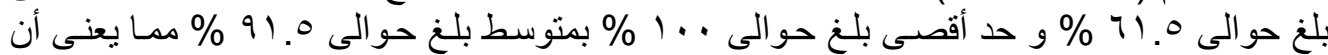

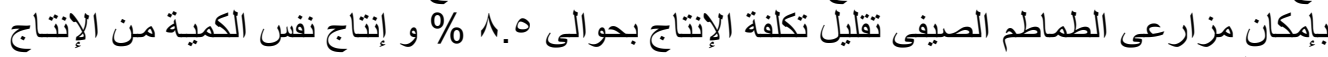

-

Fayoum J. Agric. Res. \& Dev., Vol. 26, No. 2, July, 2012 
أما فى ظل افتر اض تغير العائد إلى السعة VRS فقد تراوحت الكفاءة التقنية لإنتاج محصول

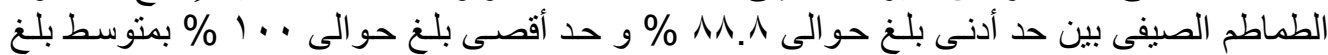

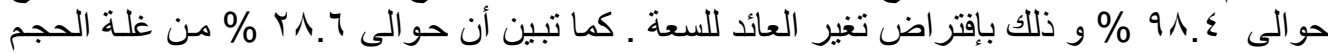

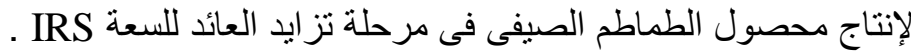

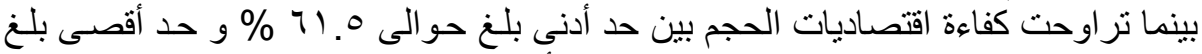

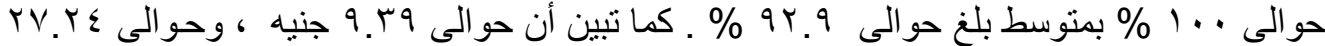

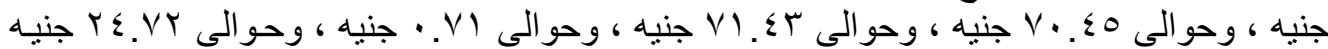

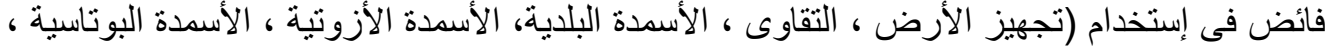

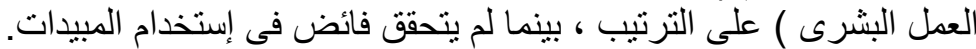

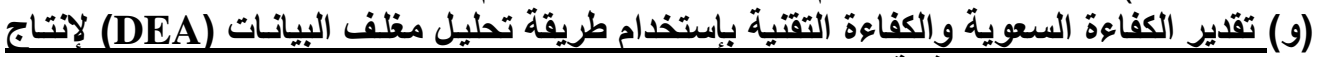

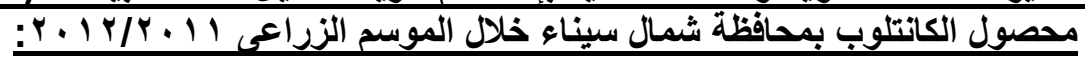

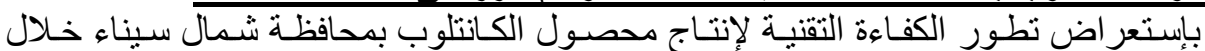

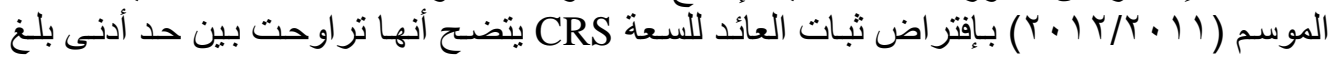

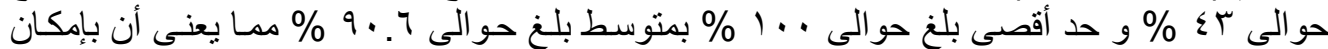

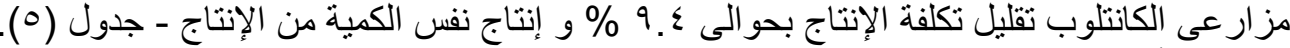

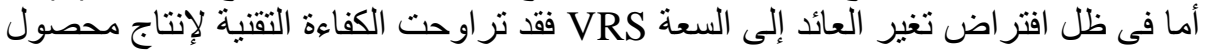

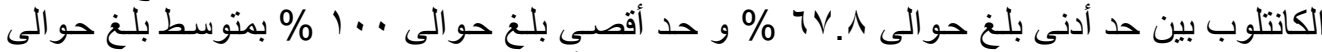

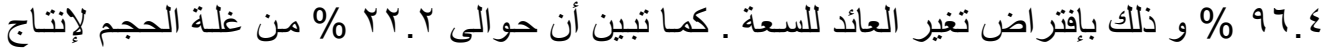

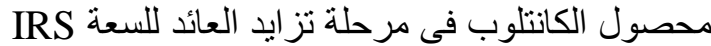

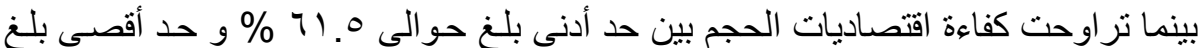

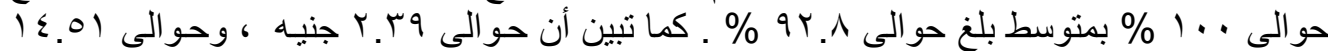

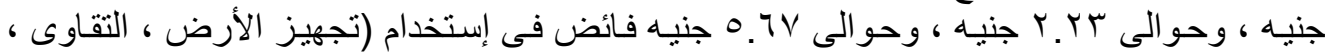

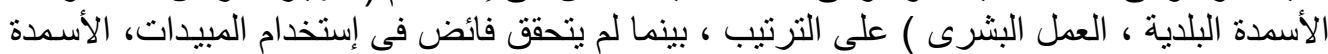

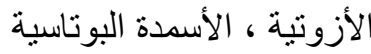
(ز) تقدير الكفاعة السعوية والكفاعة التقتية بإستخدام طريقة تحليل مغلف البيانات (DEA) لإنتاج

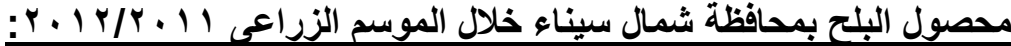

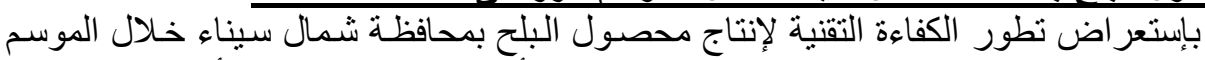

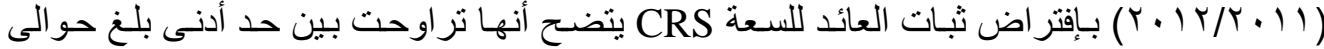

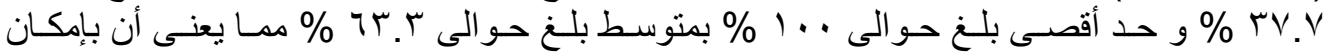

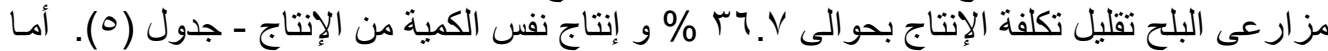

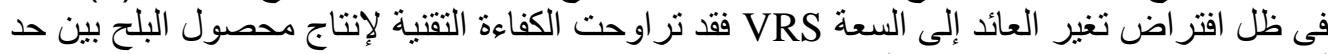

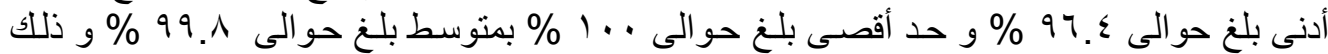

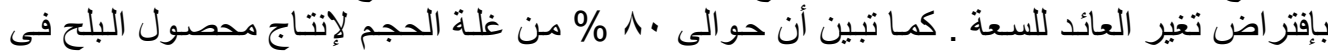

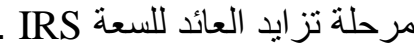

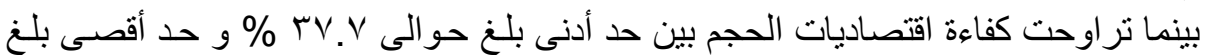

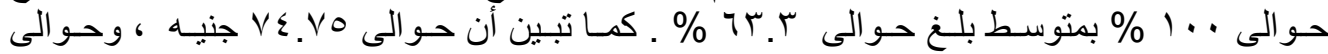

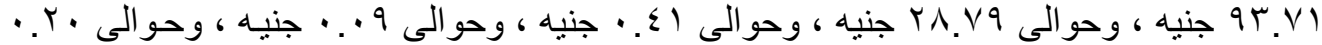

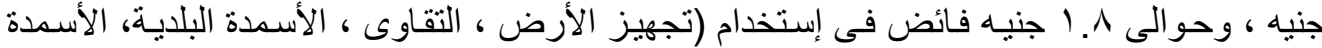

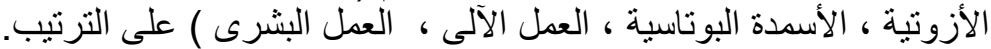

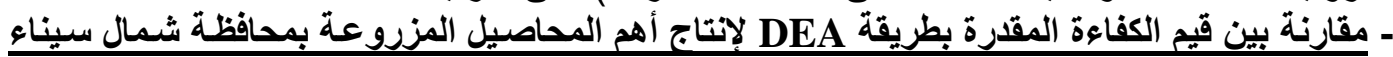

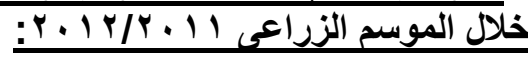
تم تقدير معامل إرتباط سبيرمان بين قيم الكفاءة المقدرة لمقارنة النتائج المتحصل عليها لقيم

Data Envelopment Analysis بطريقة تحليل مغلف البيانات فئنة

Fayoum J. Agric. Res. \& Dev., Vol. 26, No. 2, July, 2012 
rr

Variable Return To Scale و Constant Return To Scale (CRS)وفقاً (DEA) . (VRS)

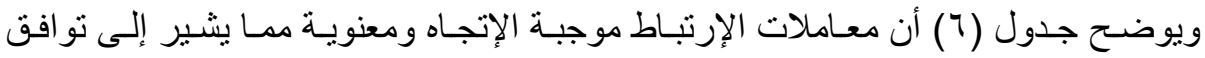

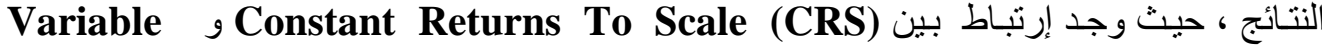
Returns To Scale (VRS)

جدول (0) : متوسط الكفاعة السعوية والكفاعة التقنية لإتـاج أهم المحاصيل الزراعية بمحافظة شمال سيناء بإستخدام طريقة تحليل مغلف البيانات ( DEA منو

\begin{tabular}{|c|c|c|c|c|c|c|c|c|c|c|c|c|c|}
\hline \multicolumn{8}{|c|}{ Slacks } & \multicolumn{3}{|c|}{ scale $^{* * * *}$} & \multicolumn{2}{|c|}{ Returns to scale } & \multirow[t]{2}{*}{ Item } \\
\hline $\mathbf{X}_{8}$ & $\mathbf{X}_{7}$ & $\mathrm{X}_{6}$ & $\mathbf{X}_{5}$ & $\mathbf{X}_{4}$ & $\mathbf{X}_{3}$ & $\mathbf{X}_{2}$ & $\mathrm{X}_{1}$ & & & & Vrs $* *$ & Crs* & \\
\hline 57.10 & $\begin{array}{c}21.6 \\
2\end{array}$ & 8.34 & 4.54 & $\begin{array}{c}101 . \\
2\end{array}$ & $\begin{array}{c}43.4 \\
9\end{array}$ & 0.00 & 8.15 & $\begin{array}{l}10.0 \\
55.0\end{array}$ & $\begin{array}{l}\text { drs } \\
\text { irs }\end{array}$ & 0.949 & 0.980 & 0.929 & الخوخ \\
\hline 3.74 & $\begin{array}{c}121 . \\
8\end{array}$ & 0.00 & 0.00 & $\begin{array}{c}131 . \\
3\end{array}$ & $\begin{array}{c}46.5 \\
3\end{array}$ & $\begin{array}{c}7.07 \\
4\end{array}$ & 13.9 & $\begin{array}{l}14.7 \\
44.1\end{array}$ & $\begin{array}{l}\text { drs } \\
\text { irs }\end{array}$ & 0.925 & 0.971 & 0.899 & الزيتون \\
\hline 0.00 & 0.00 & 0.00 & $\begin{array}{c}25.7 \\
4\end{array}$ & 0.00 & 0.00 & $\begin{array}{c}10.8 \\
4\end{array}$ & 3.08 & $\begin{array}{l}00.0 \\
72.2\end{array}$ & $\begin{array}{l}\text { drs } \\
\text { irs }\end{array}$ & 0.652 & 0.881 & 0.595 & الثعير \\
\hline 64.43 & 0.00 & 7.55 & $\begin{array}{c}53.9 \\
3 \\
\end{array}$ & $\begin{array}{c}138 . \\
6\end{array}$ & $\begin{array}{c}146 . \\
4\end{array}$ & $\begin{array}{c}197 . \\
3\end{array}$ & 6.71 & $\begin{array}{l}00.0 \\
60.0\end{array}$ & $\begin{array}{l}\text { drs } \\
\text { irs }\end{array}$ & 0.825 & 0.910 & 0.779 & الشتوى \\
\hline 24.72 & 0.00 & 0.71 & $\begin{array}{c}71.4 \\
3\end{array}$ & $\begin{array}{c}70.4 \\
5\end{array}$ & 0.00 & $\begin{array}{c}27.2 \\
4\end{array}$ & 9.39 & $\begin{array}{l}00.0 \\
28.6\end{array}$ & $\begin{array}{l}\text { drs } \\
\text { irs }\end{array}$ & 0.929 & 0.984 & 0.915 & الصيفى \\
\hline 5.67 & 0.00 & 0.00 & 0.00 & 2.23 & 0.00 & $\begin{array}{c}14.5 \\
1\end{array}$ & 2.39 & $\begin{array}{l}00.0 \\
22.2\end{array}$ & $\begin{array}{l}\text { drs } \\
\text { irs }\end{array}$ & 0.928 & 0.964 & 0.906 & الكانتلوب \\
\hline 1.80 & 0.20 & 0.09 & 0.41 & $\begin{array}{c}28.7 \\
9\end{array}$ & 0.00 & $\begin{array}{c}93.7 \\
1\end{array}$ & 74.7 & $\begin{array}{l}00.0 \\
80.0\end{array}$ & $\begin{array}{l}\text { drs } \\
\text { irs }\end{array}$ & 0.633 & 1.000 & 0.633 & البلح \\
\hline
\end{tabular}

Crs $^{*}=$ Constant Return to Scale

المصدر : جمعت وحسبت من نتائج تحليل (DEA) ومن بيانات عينة إستبيان الدر اسة.

Vrs $^{* *}=$ Variable Return to Scale

Scale $^{\star * *}$ Efficiency $=$ Crs $/$ Vrs

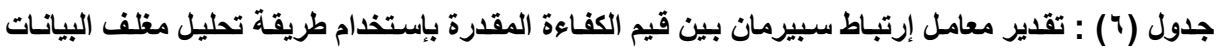

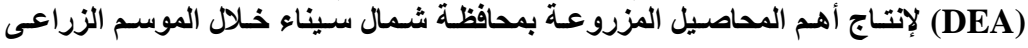

$r+\mid r / r+11$

\begin{tabular}{|c|c|c|}
\hline $\begin{array}{c}\text { Variable Returns To } \\
\text { Scale (VRS) }\end{array}$ & $\begin{array}{c}\text { Constant Returns To } \\
\text { Scale (CRS) }\end{array}$ & \\
\hline & 1 & Constant Returns To Scale (CRS) \\
\hline 1 & $0.499^{*}$ & Variable Returns To Scale (VRS) \\
\hline
\end{tabular}

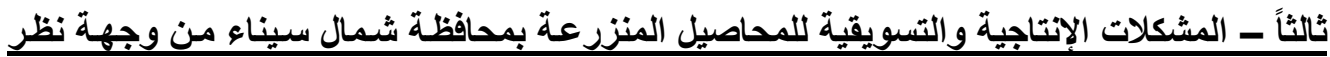

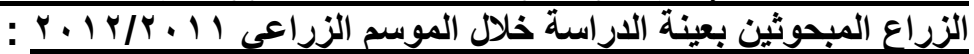

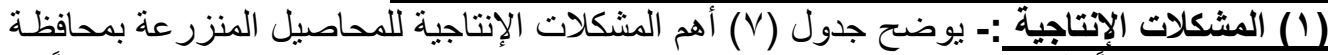

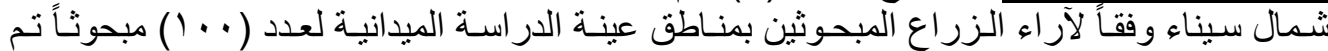

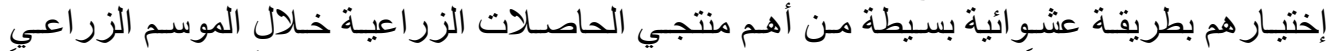

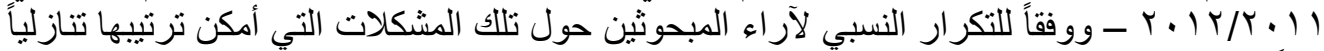

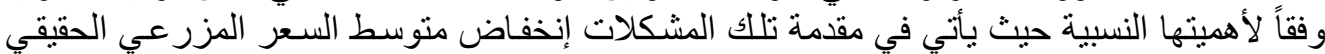

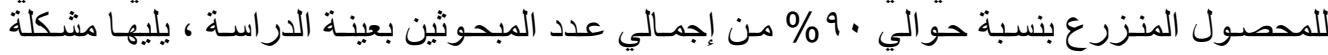

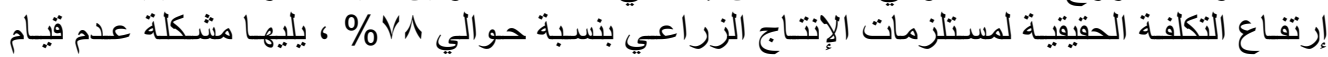

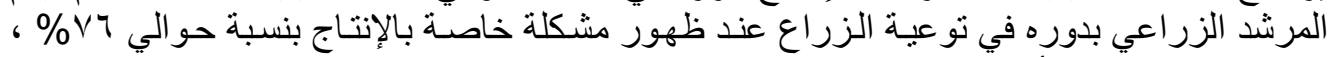

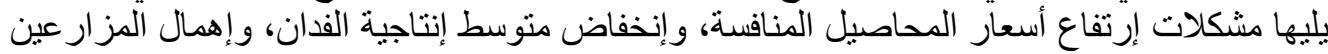

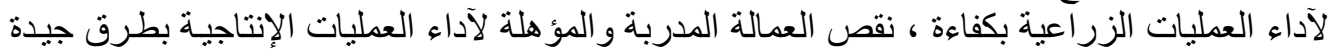

Fayoum J. Agric. Res. \& Dev., Vol. 26, No. 2, July, 2012 
\&

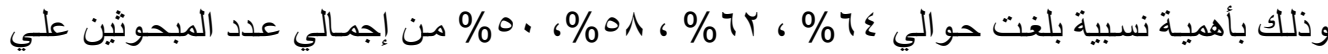
الترنيب.

جدول (V) أهم المشكلات الإنتاجية للمحاصيل المنزرعة بمحافظة شمال سيناء من وجهة نظر الزراع المبحوثين بعينة

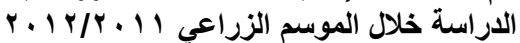

\begin{tabular}{|c|c|c|c|}
\hline$\%$ & 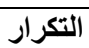 & 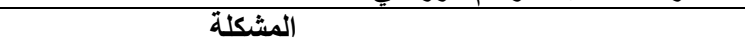 & p \\
\hline 9. & 9. & إنخفاض متوسط السعر المزرعي الحقيقي للمحصول المنزرع. & 1 \\
\hline$\vee \wedge$ & $\mathrm{VA}$ & إرتفاع التكلفة الحقيقية لمستلزمات الإنتاج الزراعي. & r \\
\hline$\vee 7$ & $\sqrt{ } 7$ & عدم قيام المرشد الزر اعي بدوره في توعية الزراع. & $r$ \\
\hline $7 \leq$ & $T \leq$ & إرتفاع أسعار المحاصيل المنافسة. & $\varepsilon$ \\
\hline Tr & Tr & إنخفاض متوسط إنتاجية الفدان. & 0 \\
\hline $0 \wedge$ & 01 & عدم قيام الزراع بأداء العمليات الزر اعية بكفاءة. & 7 \\
\hline 0. & 0. & نقص العمالة المدربة و المؤهلة لآداء العمليات الإنتاجية بطرق جيدة. & V \\
\hline
\end{tabular}

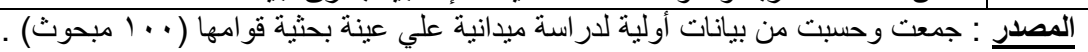

(Y) المشكلات التسويقية:- نشير نتائج جدول (^) إلي أهم مشكلات تسويث المحاصيل المنزر عـة

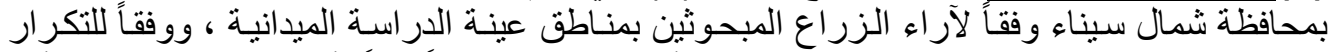

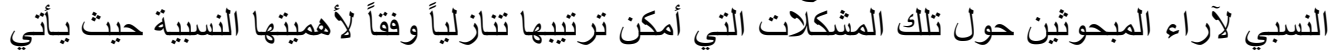

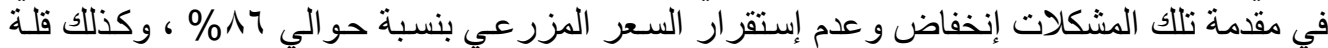

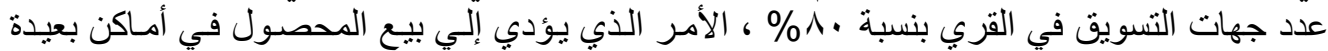

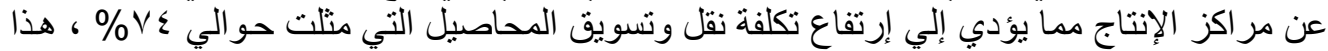

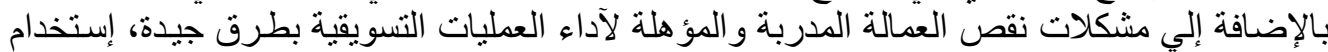

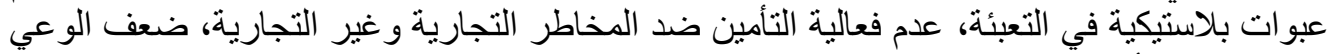

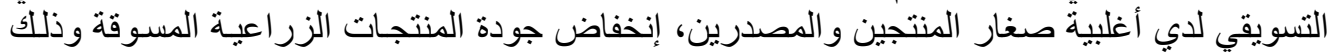

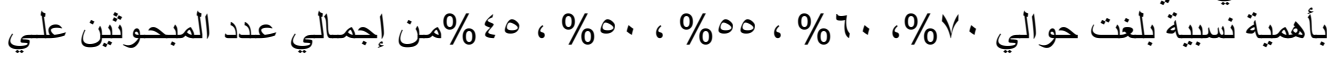
الترنبب.

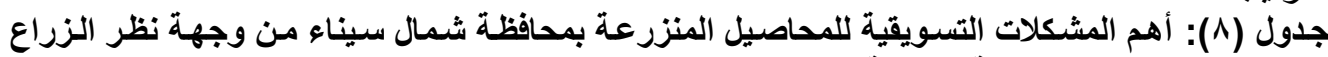

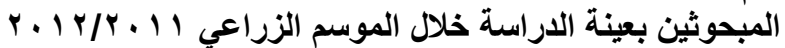

\begin{tabular}{|c|c|c|c|}
\hline$\%$ & 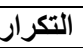 & المشكلة - الة & م \\
\hline ᄉт & 14 & إنخفاض و عدم إستقرار السعر المزرعي الحقيقي. & 1 \\
\hline$\wedge$. & $\wedge$. & قلة عدد جهات التسويق. & r \\
\hline $\mathrm{V} \leqslant$ & $\mathrm{V} \leqslant$ & إرتفاع تكلفة التسويق & r \\
\hline $\mathrm{V} \cdot$ & $\mathrm{V} \cdot$ & نقص العمالة المدربة و المؤ هلة لآداء العمليات التسويقية بطرق جيدة. & $\varepsilon$ \\
\hline 7. & 7. & إستخدام عبو ات بلاستنيكية في التعبئة. & $\circ$ \\
\hline 00 & 00 & عدم فعالية التأمين ضد المخاطر التجارية وغير التجارية. & 7 \\
\hline 0. & 0 . & ضعف الوعي التسويقي لاي أغلبية صغار المنتجين والمصدرين. & $\mathrm{V}$ \\
\hline$\leqslant 0$ & $\varepsilon 0$ & إنخفاض جودة المنتجات الزر اعية المسوقة. & $\Lambda$ \\
\hline
\end{tabular}

المصدر : جمعت وحسبت من بيانات أولية لدر اسة ميدانية علي عينة بحثية قو امها ( . . ( مبحوث).

رابعاً: الحلول المقترحة لحل المشكلات الإتتاجية والتسويقية للمحاصيل المنزرعة بمحافظة شمال سبناء

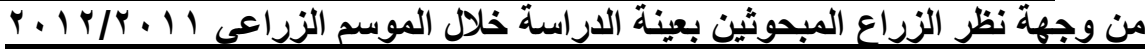

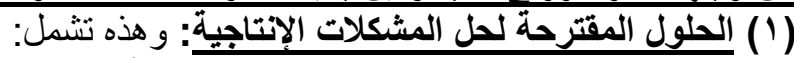

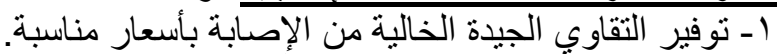

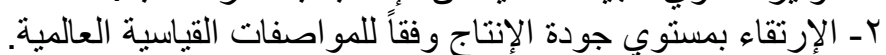

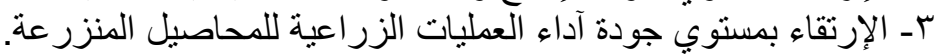

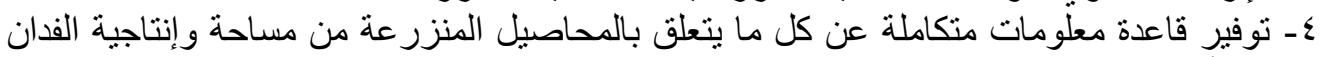

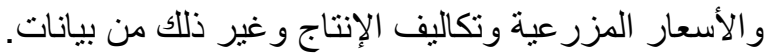
0ـ توفير نظام للتمويل يحمي المنتجين من المخاطر .

Fayoum J. Agric. Res. \& Dev., Vol. 26, No. 2, July, 2012 
Ho

7- زيادة وعي المنتجين بأهمية الإنتاج لغرض التصدير وما يترتب عليه من جلب عملات أجنبية تخدم عملية التنمية الإقتصادية.

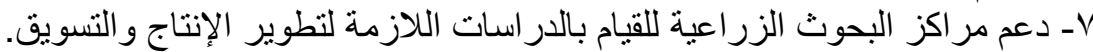

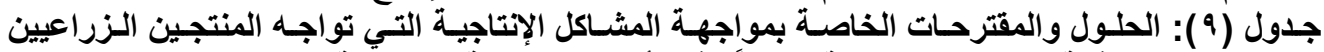

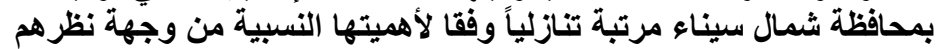

\begin{tabular}{|c|c|c|c|}
\hline$\%$ & التكرار & الحلول المقترحة & p \\
\hline 9. & 9 . & توفير التقاوي الجيدة الجيدة الخالية من الإصابة بأسعار مناسبة. & 1 \\
\hline$\Lambda \mathrm{T}$ & $\wedge 7$ & الإرتقاء بمستوي جودة الإنتاج وفقاً للمو اصفات القياسية العالمية. & $r$ \\
\hline$\Lambda$. & $\Lambda$. & الإرتقاء بمستوي جودة آداء العمليات الزر اعية للمحاصيل المنزرعة. & $r$ \\
\hline Vo & Vo & 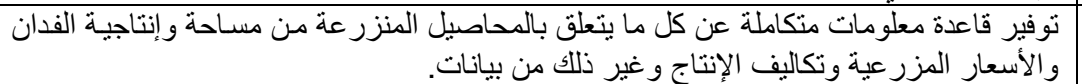 & $\varepsilon$ \\
\hline 77 & 77 & توفير نظام للتمويل يحمي المنتجين من المخاطر. & 0 \\
\hline$O \Lambda$ & 01 & أجنيبة تخدم عملية التنمية الإقتصنية الإنتاجية. لغرض التصدير التصدير وما يترتب عليه من جلب عملات & 7 \\
\hline 00 & 00 & دعم مر اكز البحوث الزر اعية للقيام بالدر اسات اللازمة لتطوير الإنتاج و التسويق. & $\mathrm{V}$ \\
\hline
\end{tabular}

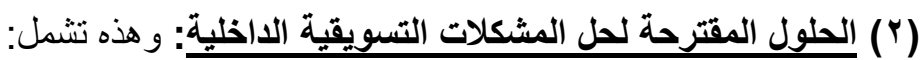

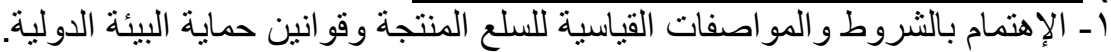
r- زيادة الأسعار الزراعية بما يتفق مع زيادة التكاليف الإنتاجية الفدانية.

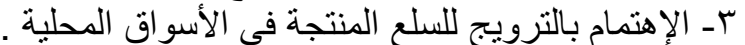

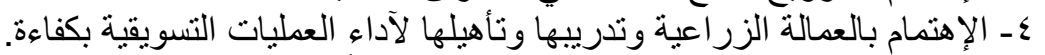

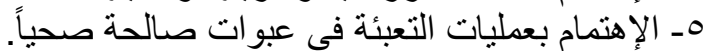

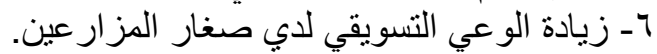

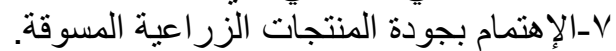

جدول ( • (): الحلول والمقترحات الخاصة بمواجهة المشاكل التسويقية التي تواجه المنتجين الزراعيين

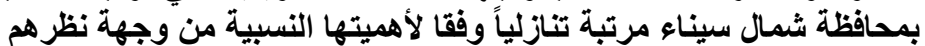

\begin{tabular}{|c|c|c|c|}
\hline$\%$ & 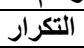 & الحلول المقترحة & م \\
\hline 9. & 9. & الإهتمام بالشروط و المو اصفات القياسية للسلع المنتجة وقو انين حماية البيئة الدولية. & 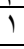 \\
\hline NT & הт & زيادة الأسعار الزر اعية بما يتفق مع زيادة التكاليف الإنتاجية الفدانية. & r \\
\hline A. & A. & الإهتمام بالترويج للسلع المنتجة في الأسو اق المحلية & $r$ \\
\hline Vo & Vo & الإهتمام بالعمالة الزر اعية وتدريبها وتأهيلها لآداء العمليات التسويقية بكفاءة. & $\varepsilon$ \\
\hline 74 & 77 & الإ هتمام بعمليات التعبئة في عبوات صالحة صحياً. & 0 \\
\hline 01 & 01 & زيادة الوعي التسويقي لاي صغار المزارعين. & 7 \\
\hline 00 & 00 & الإهتمام بجودة المنتجاتِ الزر اعية المسوقة. & $\bar{v}$ \\
\hline
\end{tabular}

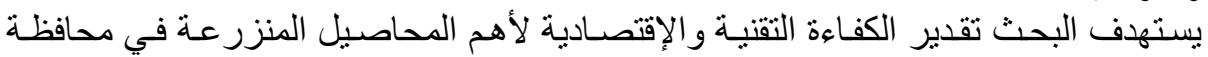

الملخص والتوصيات

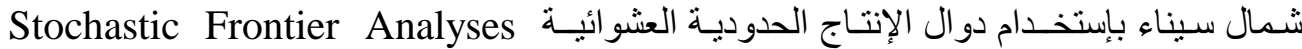

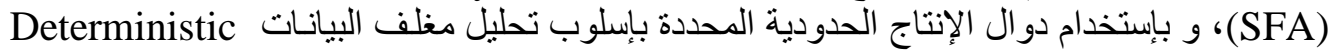
Envelopment Analysis (DEA)

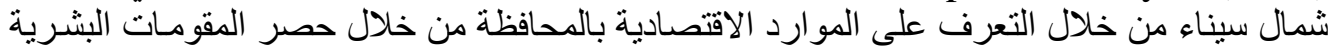
و الزر اعية لإظهار دور ها في عملية التنمية . وقد أوضحت نتائج تقدير الكفاءة الفنية بإستخدام دو ال الإنتاج الحدودية العشوائية لإنتاج لأهم

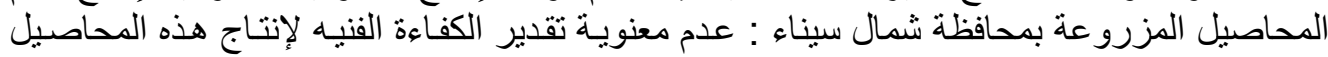

Fayoum J. Agric. Res. \& Dev., Vol. 26, No. 2, July, 2012 
m

بطريقة (MLE) للتوزيع Half-Normal و التوزيع Truncated ، مما بشير إلى أفضلية منهجية مغلف البيانات (DEA) عن منهجية تحليل الحدودية العشو ائية (SFA)

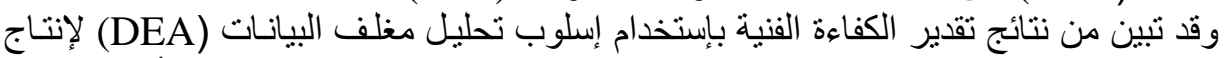

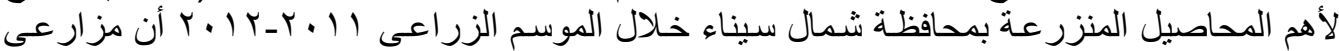

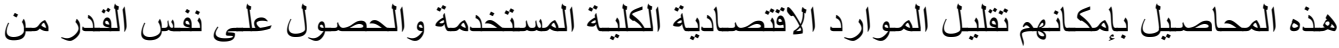

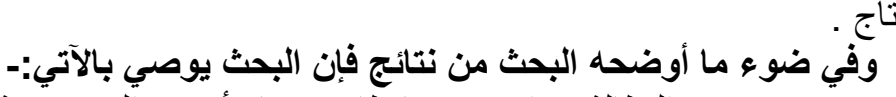

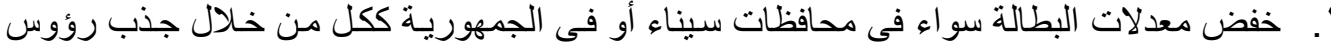

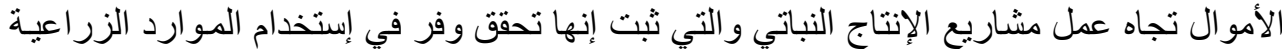

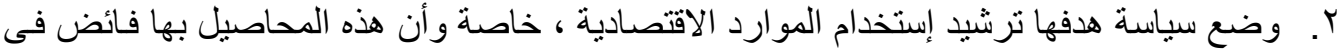

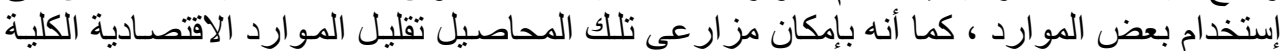

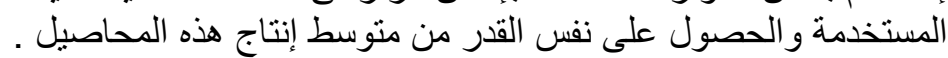

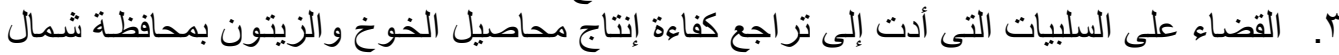

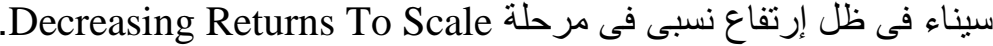

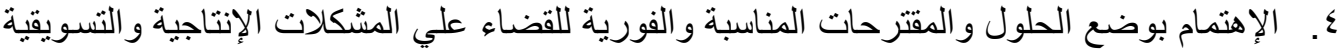

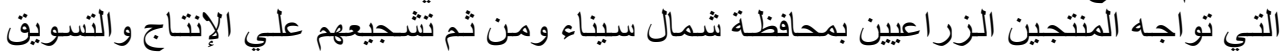

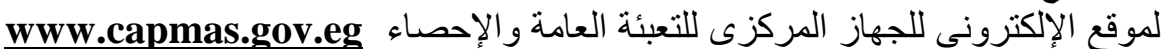

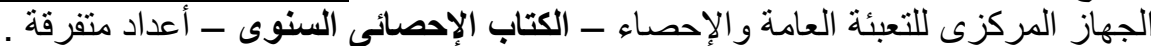

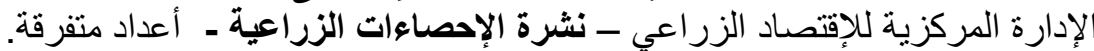

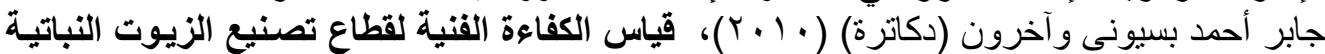

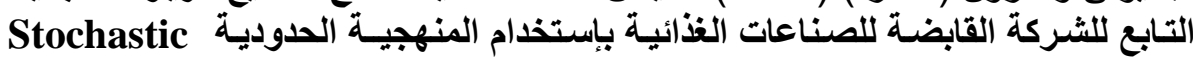
Frontier Analyses (SFA)

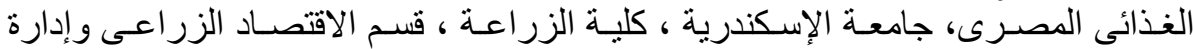

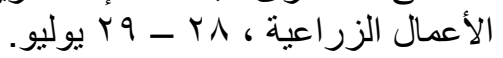

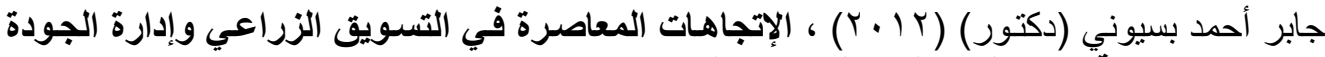

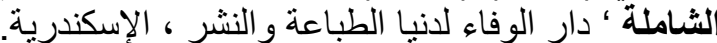

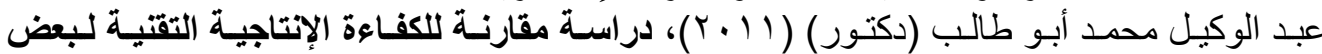

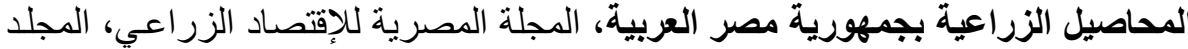

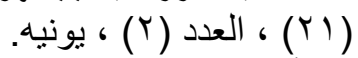

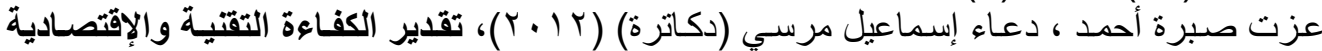
لأهم المحاصيل الزيتية في محافظة أسيوط ، المجلة المصرية لونية للإقتصـاد الزر اعي، المجلد

$$
\text { (Y) }
$$

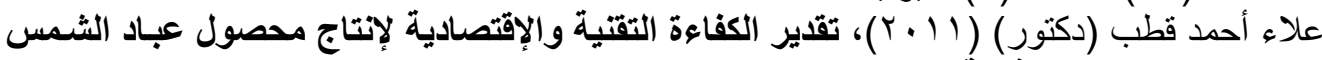

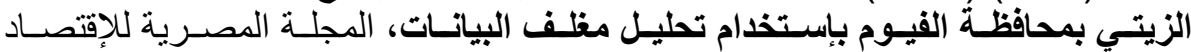

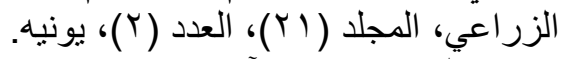

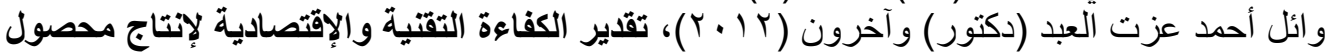
الأرز في مصر، مجلة الجمعية السعودية للعلوم الزر اعية، المجلد (1) (1) ، العدد (1) (1) ، يناير.

Fayoum J. Agric. Res. \& Dev., Vol. 26, No. 2, July, 2012 
rv

Barry R., and Ralph M.(1998), Quantitative Analysis for Management, $3^{\text {rd }}$ Edition, Allyn Bacon Inc. USA.

Coelli, T.J. (1996), A Guide to DEAP Version 4.1: A Data Envelopment Analysis (Computer) Program. CEPA Working Paper 96/08, Dept. ofEconometrics, University of New England, Armidale, Australia.

Daniel W. and Terrel J. (1989), Business Statistics for Management and Economics, Houghton Mifflin Company, USA

Farrel, (1957), Measuring the Technical Efficiency of Company, Ed., Activity of Production and Allocation, Cowles Commission for Research in Economics, Monograph No 13, Wiley, New York.

\title{
ESTIMATE OF THE TECHNICAL AND ECONOMIC EFFICIENCY OF THE MOST IMPORTANT AGRICULTURAL CROPS IN NORTH SINAI GOVERNORATE
}

Gaber A. Bassyouni* ; Asem K. Abd El-Hamied and Ryad I. Mostafa***

* Faculty of Agriculture (Saba Basha), Alexandria University

** Faculty of Agriculture - Al Azhar University - Cairo

*** Faculty of Invironmental Agricultural Sciences, (EI-Arish) Seuz Canal

University

\begin{abstract}
The main objective of the research is studying access to use of economicresourdes available to produce some agricultural crops in North Sinai Governorate to raise the proportion of self-sufficiency of these crops by measuring the efficiency of technical and economic efficiency and estimate the size of the surplus or deficit in the resources used in the cultivation of crops in North Sinai Governorate.

Descriptive and statistical analysis has been used to achieve the objectives of the research. The study depends on the secondary data, which collected from local sources during the study period. Aquestionannaire through personal interviews was used to collect data from (100) respondents randomly selected from villages of Governorate.

The study showed when estimating the allocative efficiency for the production of peach crop, it was found that the average efficiency index allocative during the period $(2002-2011)$ was about $92.9 \%$ in the case of
\end{abstract}

Fayoum J. Agric. Res. \& Dev., Vol. 26, No. 2, July, 2012 
Constant Returns to Scale (CRS), and about $98 \%$ in the case of Variable Return to Scale (VRS), which it means that proucers of peach crop can decrease the production cost of peach crop by $7.1 \%$ and $2 \%$ respectively and can produce the same level production quantity of peach crop. For olive crop, the average efficiency index distribution around $89.9 \%$ in the case of CRS and about $97.1 \%$ in the case of VRS. For bearly, winter tomatoes, summer tomatoes, alcantlob and palm crops, the average efficiency index distribution around $59.5 \%, 77.9 \%, 91.5 \%, 90.6 \%$, and $63.3 \%$ in the case of CRS respectively, while in the case of VRS it was about $88.1 \%, 91 \%, 98.4 \%$, and $99.8 \%$ respectively.

Some recommendations from this research had been discussed to improve the technical and economic efficiency for agricultural production in North Sinai Governorate. 